\title{
Review on "Retardation of Fatigue Crack Propagation under Plane Strain Condition due to a Single Overload"
}

\author{
by
}

\author{
Atsushi SUGETA* and Yoshihiko UEMATSU** \\ (The authors in original paper: Masahiro JONO, Tetsuro KANAYA, \\ Atsushi SUGETA and Makoto KIKUKAWA)
}

\begin{abstract}
Retardation of fatigue crack propagation due to a single tensile overload and crack closure behavior were investigated on a high tensile strength steel, HT-80 and an aluminum alloy, A5083-O by using the unloading elastic compliance method. Although the delayed retardation was observed at the specimen surface where the plane stress condition dominated, retardation of fatigue crack propagation was found to occur immediately after a peak overload at the interior of the specimen where the plane strain condition was developed. In the latter case, the crack tip blunting due to an overload, which might be the reason of the nodelayed retardation, was confirmed by fractography and also by the loaddisplacement hysteresis curve. Moreover, it was found that the retardation behavior of fatigue cracks which initiated and propagated from the root of the blunted crack could not be explained only by the change of the macroscopically measured crack tip opening level.
\end{abstract}

\section{Key words:}

fatigue crack, retardation, single overload, plane strain condition, crack closure behavior

\section{Introduction}

The propagation behavior of fatigue cracks is significantly affected by load variations. Numerous studies have been conducted particularly on the retardation phenomenon of crack propagation caused by a single overload. The load level ${ }^{1)}$, overload ratio $^{2)}$, test specimen dimension, especially plate thickness $^{3)}$, material strength ${ }^{4)}$, etc., have been identified as factors that affect the retardation phenomenon. However, apart from detailed mechanisms such as these influential factors, it can be inferred that a larger plastic zone size causes a stronger effect because the delay phenomenon is caused by crack propagation in the plastic zone formed by a tensile overload. Several models ${ }^{5), 6)}$ have been considered to represent the retardation in crack propagation owing to the plastic region. In many cases, the crack propagation length is measured on the specimen surface. In this case, it is reported ${ }^{1), 7)}$ that the delay phenomenon does not occur immediately after overloading, but rather exhibits delayed retardation in which the crack propagation rate becomes the lowest after the crack has propagated to some extent. However, conventionally, the fatigue crack propagation behavior, especially the behavior under a variable load, differs ${ }^{8)}$ between the specimen surface in the plane stress condition and the interior of the specimen close to the plane strain condition. From fractography results, it has been observed that the delayed retardation is either lower" ${ }^{9)}$ in the interior of the specimen compared to that on the specimen surface, or is not observed ${ }^{10)}$ because the maximum retardation occurs immediately after overloading. It has also been reported that delayed retardation is not observed ${ }^{11)}$ in the interior even by dynamic measurement using the ultrasonic method. For the cause and mechanism of this retardation phenomenon, the crack tip blunting because of the overload and crack closure phenomenon ${ }^{12)}$ are considered in addition to the compressive residual stress from the plastic region mentioned above.

The authors have also conducted considerable research on the crack closure phenomenon. In addition to finding that it is extremely effective ${ }^{13), 14)}$ to consider the effective stress intensity factor range $\Delta K_{\text {eff }}$ for the estimation of the crack propagation rate under a stationary cyclic variable load, it was reported that the retardation could be explained ${ }^{13)}$ by the change of $\Delta K_{\text {eff }}$ in the region where the load level is relatively high even under a two stage high-low double variable load. However, because Elber pointed out that the effect of load variation as well as the effect of the stress ratio can be explained, it has been shown that many delay phenomena can be explained qualitatively by the delay

$\dagger \quad$ Received Oct.23,2020 @2021 The Society of Materials Science, Japan

This paper was originally published in Japanese in J. Soc. Mater. Sci., Jpn. Vol.32, No.363, pp.1383-1389, (1983).

* Member: Hiroshima University, Kagamiyama, Higahi-Hiroshima, 738-8527.

** Member: Gifu University, Yanagido, Gifu 501-1193. 
T able 1 Chemical composition of materials used. (\%)

\begin{tabular}{c|c|c|c|c|c|c|c|c|c|c}
\hline Material & $\mathrm{C}$ & $\mathrm{Mn}$ & $\mathrm{Si}$ & $\mathrm{P}$ & $\mathrm{S}$ & $\mathrm{Cu}$ & $\mathrm{Ni}$ & $\mathrm{Cr}$ & $\mathrm{Mo}$ & $\mathrm{V}$ \\
\hline $\mathrm{HT} 80$ & 0.12 & 0.83 & 0.33 & 0.011 & 0.009 & 0.25 & 0.81 & 0.44 & 0.40 & 0.04 \\
\hline Material & $\mathrm{Mg}$ & $\mathrm{Mn}$ & $\mathrm{Si}$ & $\mathrm{Ti}$ & $\mathrm{Fe}$ & $\mathrm{Cr}$ \\
\hline A5083-0 & 4.46 & 0.63 & 0.18 & 0.017 & 0.19 & 0.12 \\
\hline
\end{tabular}

phenomenon after single overloading. Additionally, Matsuoka et al. proposed ${ }^{7}$ a model that explains the delayed retardation considering the crack closure behavior. Recently, the crack closure phenomenon has been considered the most effective factor for explaining the delay phenomenon. However, there are very few quantitative studies based on the actual measurement of the crack opening point after overloading. Moreover, most of these cases seem to have ended ${ }^{15)}$ in a rather rough study and there seems to be no detailed investigation.

Therefore, in this study, we measure the crack propagation retardation caused by a single overload and the crack closure behavior dynamically in real time using the unloading elastic compliance method ${ }^{13)}$; the authors have been developing this method and improving its accuracy. Subsequently, we report the delay phenomenon of fatigue crack propagation inside the specimen close to the plane strain condition, which is important for practice use, in relation to the crack closure behavior, and verify the variation in retardation at the specimen surface and interior.

\section{Test material, specimen, and method}

The test materials include high tensile strength tempered steel HT80 (quenched at $930{ }^{\circ} \mathrm{C}$, tempered at $650{ }^{\circ} \mathrm{C}$ ) and corrosion-resistant annealed aluminum alloy A5083-O $\left(360^{\circ} \mathrm{C}\right.$, $1 \mathrm{~h}$ retention); their chemical compositions and mechanical properties are listed in Tables I and II, respectively. Figure 1 shows the shape and dimensions of the $\mathrm{CT}$ test specimen used. As shown in the figure, the test specimen characterizes a $60^{\circ}$ $\mathrm{V}$-shaped side groove with a depth of $1.5 \mathrm{~mm}$ and a tip radius of $0.5 \mathrm{~mm}$. Therefore, the stress conditions of the crack tip were relatively ${ }^{16)}$ similar to the plane strain condition of the specimen interior in almost the entire region of the crack front. Additionally, the effect of the surface that raises the opening point was eliminated when measuring the crack opening point. An electro-hydraulic servo fatigue testing machine with a capacity of $\pm 100 \mathrm{kN}$ was used for the test. The single overload tests were performed under two types of conditions with the $K$ value controlled at a pulsating tension $(R=0)$. The first condition is to keep the reference stress intensity factor $K_{0}$ at a constant of $21.1 \mathrm{MPa} \cdot \mathrm{m}^{1 / 2}$, changing the overload ratio $r$ from 1.4 to 2.5 as shown in Table III. The second condition is to keep $r$ at 2, changing $K_{0}$ from 9.3 to $63.2 \mathrm{MPa} \cdot \mathrm{m}^{1 / 2}$.
T able 2 Mechanical properties of materials used.

\begin{tabular}{l|c|c|c}
\hline Material & $\begin{array}{c}\text { Yield point } \\
\left(\begin{array}{c}\text { ) Proof } \\
\text { stress } \\
\text { (MPa) }\end{array}\right.\end{array}$ & $\begin{array}{c}\text { Tensile } \\
\text { strength } \\
\text { (MPa) }\end{array}$ & $\begin{array}{c}\text { Elongation } \\
\text { (\%) }\end{array}$ \\
\hline HT80 & 765 & 814 & 34.0 \\
A5083-0 & $(140)$ & 297 & 26.0 \\
\hline
\end{tabular}

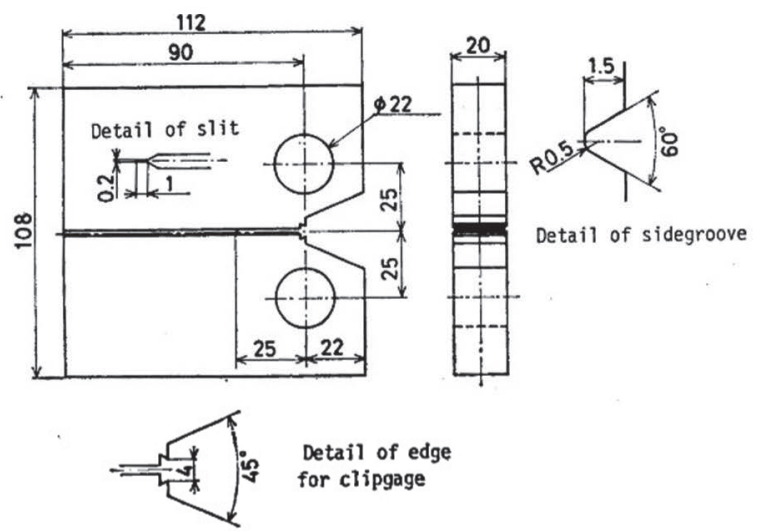

Fig. 1 T est specimen configuration.

Table 3 T est conditions.

\begin{tabular}{r|c|l}
\hline No. & $K_{0}(\mathrm{MPa} \sqrt{\mathrm{nI}})$ & $r=K_{p} / K_{0}$ \\
\hline 1 & 21.1 & 1.4 \\
2 & 21.1 & 1.6 \\
3 & 21.1 & 1.8 \\
4 & 21.1 & 2.0 \\
5 & 21.1 & 2.25 \\
6 & 21.1 & 2.5 \\
7 & 9.3 & 2.0 \\
8 & 15.5 & 2.0 \\
9 & 31.0 & 2.0 \\
10 & 63.2 & 2.0 \\
\hline
\end{tabular}

The cyclic frequency was set to $10 \mathrm{~Hz}$, but condition 7 with a slow crack propagation rate was carried out at $40 \mathrm{~Hz}$ and condition 10 with a fast propagation rate at $5 \mathrm{~Hz}$. Additionally, the crack length and crack opening point were dynamically automatically measured ${ }^{17)}$ by the unloading elastic compliance method using a minicomputer without changing the test frequency.

To compare the crack propagation behavior at the specimen surface and interior, a CT test specimen with the same dimensions as Fig. 1 and without the side groove was used, and the test was performed under condition 8 of Table III. The 
crack length and crack opening point were measured on the specimen surface by a moving reading microscope and a strain gauge (gauge length $5 \mathrm{~mm}$ ) attached to the surface $(5 \mathrm{~mm}$ below the crack). The behavior of the specimen interior was measured by the unloading elastic compliance method.

\section{Variation in retardation of crack propagation at specimen surface and interior}

Figures 2 and 3 show the crack propagation and crack opening point behaviors, respectively, following a single overload at the specimen surface and interior of the hightensile strength steel HT80 material obtained from the specimen without the side groove. Figure 2 shows the relationship between the crack propagation length $\Delta l$ and the number of cycles $\Delta N$ after single overloading, whereas Fig. 3(a) shows the relationship between the crack propagation rate $\mathrm{d} l / \mathrm{d} n$ and $\Delta l$ obtained from this relationship. The maximum retardation occurs after the crack has propagated by approximately $0.3 \mathrm{~mm}$ on the specimen surface indicated by solid circles in the figure. The rate then recovers as the crack propagates, indicating delayed retardation. The maximum retardation point of the delayed retardation appears at a crack propagation length of approximately $40 \%$ of the plastic zone size $\omega_{\mathrm{p}}=(1 / 2 \sqrt{2} \pi)\left(K_{\max } / \sigma_{y}\right)^{2}$, where $K_{\max }$ is the maximum value of $K, \sigma_{\mathrm{y}}$ is the yield stress in the plane strain condition owing to a single overload. The crack length exhibiting the maximum retardation is almost consistent with the conventionally reported plastic zone size of approximately $1 / 3$ to $1 / 2^{9), 18)}$. In contrast, the crack propagation behavior of the specimen interior measured continuously during the test by the unloading elastic compliance method indicated by open circles causes maximum retardation immediately after overloading unlike the behavior at the surface. Subsequently, the degree of

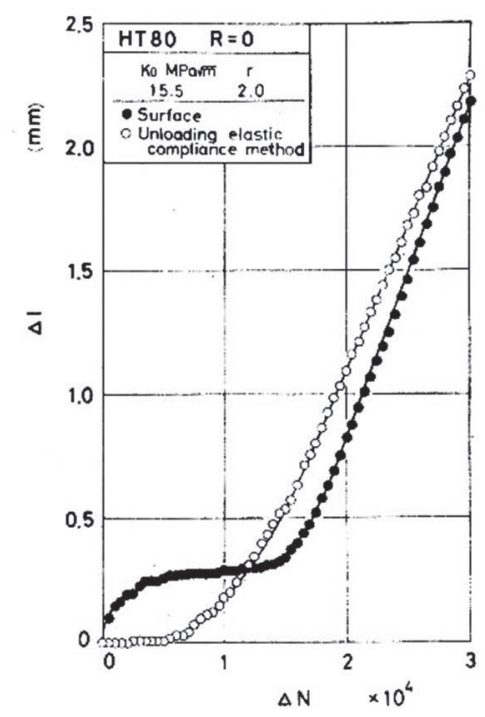

Fig. 2 Comparison of fatigue crack propagation behaviors following a single tensileoverload at specimen surface and int erior.

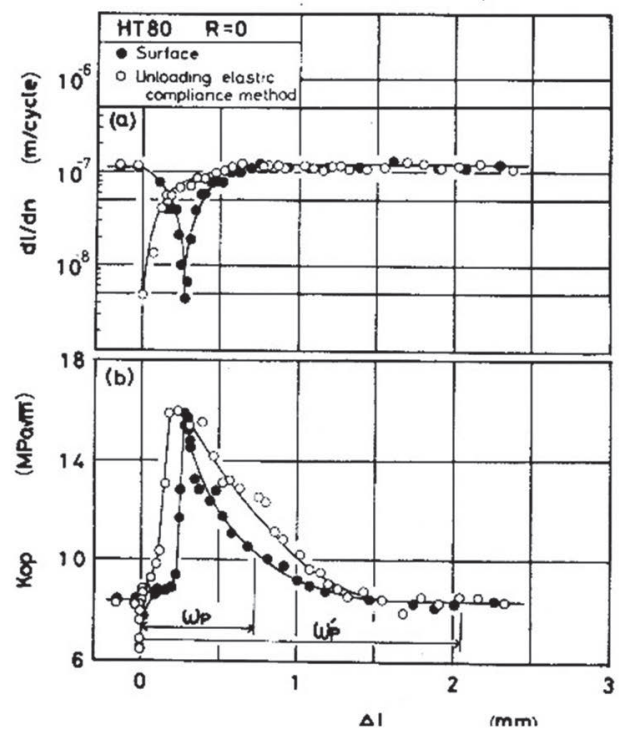

Fig. 3 Comparison of fatigue crack propagation rates and crack closure behaviors following a single tensile ov erload at specimen surface and interior.

retardation decreases as the crack propagates. Both behaviors at the specimen surface and interior return to a steady propagation rate under a constant amplitude load after the crack has propagated to the plane strain plastic zone size owing to the overload. Figure 3(b) shows the behavior of the crack opening point $K_{\mathrm{op}}$ after the overload. The crack opening point decreases once possibly because of crack tip blunting caused by the overload on both the specimen surface and interior, then gradually increases to a point higher than the steady value with respect to the reference stress intensity factor, showing a maximum value at a certain crack propagation length. The crack opening point then gradually decreases and returns to a steady value to the reference load after crack propagation of approximately 3 times the plane-strain plastic zone size. In this figure, $\omega_{\mathrm{p}}$ ' represents the plastic zone size of the plane stress condition. The crack propagation length at which the crack opening point measured on the specimen surface shows the maximum value corresponds well with the crack length at which the crack propagation on the surface causes the maximum retardation. However, the crack length at which the crack opening point returns to the steady value does not correspond to the crack length at which the retardation in crack propagation ends. Conversely, the behavior of the average crack opening point including the specimen interior does not correspond to the retardation of the crack propagation rate, and the crack propagation exhibits maximum retardation despite the decrease of the crack opening point $K_{\text {op }}$ and the increase of the effective stress intensity factor range $\Delta K_{\text {eff }}$ immediately after overloading. Furthermore, the crack opening point gradually increases with the crack propagation and $\Delta K_{\text {eff }}$ decreases, whereas the degree of retardation in the crack propagation decreases. Moreover, it seems that the position of 
the maximum value of the crack opening point and crack propagation length which returns to the steady value do not necessarily correspond to the retardation phenomenon of the propagation rate. Therefore, in the next section, the retardation behavior of the specimen interior is determined using the test specimen with the side groove, and the behavior under the plane strain condition is quantitatively considered.

\section{Fatigue crack propagation behavior following a single overload under plane strain condition}

Figure 4 shows the relationship between $\Delta l$ and $\Delta N$ of a single overload test in which the reference stress intensity factor $K_{0}$ is set as $21.1 \mathrm{MPa} \cdot \mathrm{m}^{1 / 2}$ and the overload ratio $r$ $\left(=K_{\mathrm{p}} / K_{0}\right)$ is changed to six types in the high tensile strength steel HT80 material test specimen with the side groove. No delayed retardation was observed in any of the tests, and the maximum retardation in the crack propagation rate occurred immediately after overloading. Subsequently, the rate gradually increases with cyclic loading and returns to the steady value with respect to the reference stress intensity factor. The number of cycles and crack length which the crack propagation rate to return to the steady value and crack arrest immediately after overloading increases as the overload ratio $r$ increase.

Figures 5 to 7 show the relationship between the crack propagation length $\Delta l$, crack propagation rate $\mathrm{d} l / \mathrm{d} n$, and crack opening point $K_{\mathrm{op}}$ after overloading, and $\omega_{\mathrm{pi}}$ in the figures represents the plane strain plastic zone size caused by a single overload; the subscript $i$ corresponds to the test condition number. The crack opening point $K_{\mathrm{op}}$ decreases once immediately after overloading under all test conditions, then gradually increases and becomes higher than the steady value with respect to the reference stress intensity factor $K_{0}$, showing

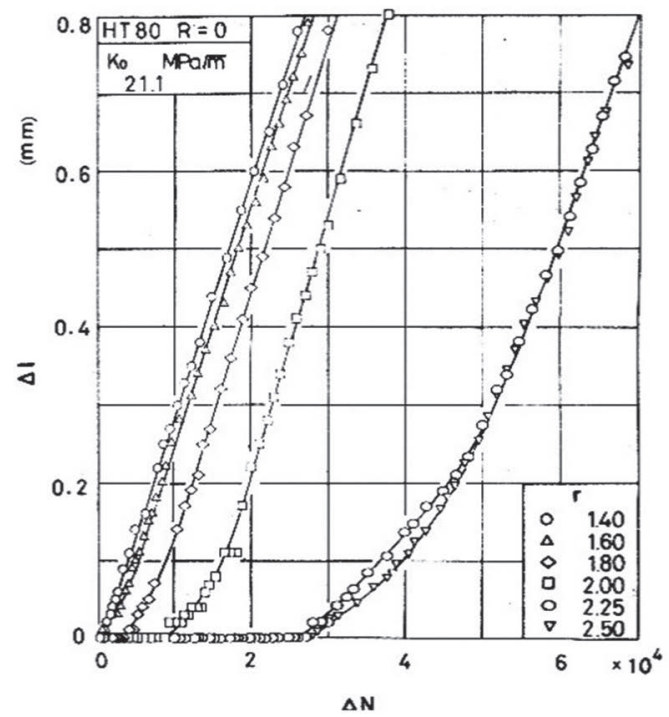

Fig. 4 Fatigue crack propagation behavior following a single tensile ov erload under plane strain condition.

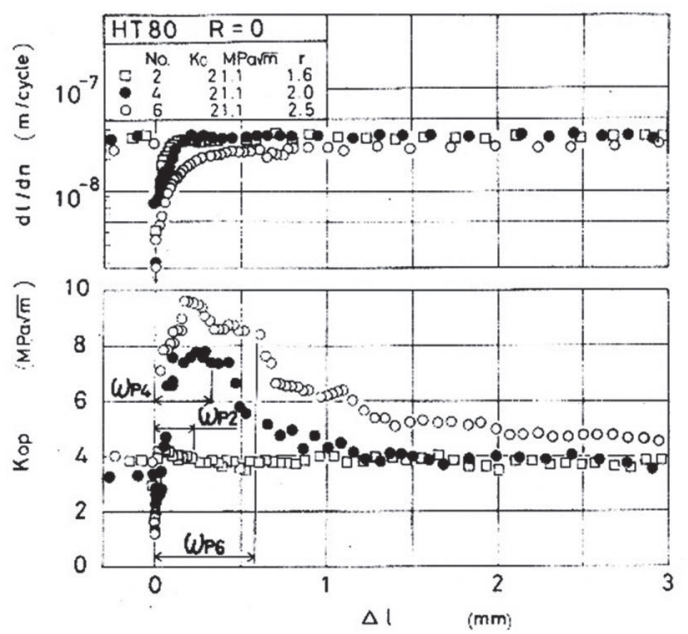

Fig. 5 Crack propagation rate and crack closure behavior following a single overload $\left(K_{0}=21.1 \mathrm{MPa} \sqrt{\mathrm{m}}, r=1.6 \sim 2.5\right)$

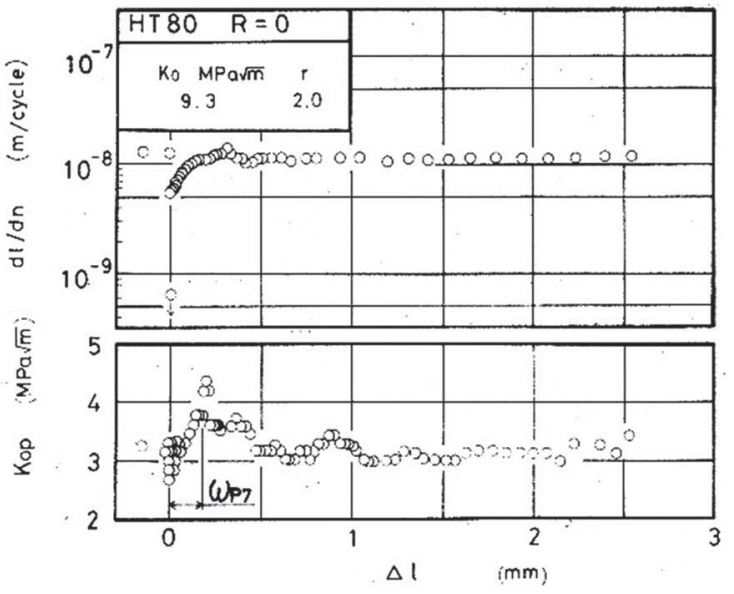

Fig. 6 Crack propagation rate and crack closure behavior following a single overload $\left(K_{0}=9.3 \mathrm{MPa} \sqrt{\mathrm{m}}, r=2\right)$

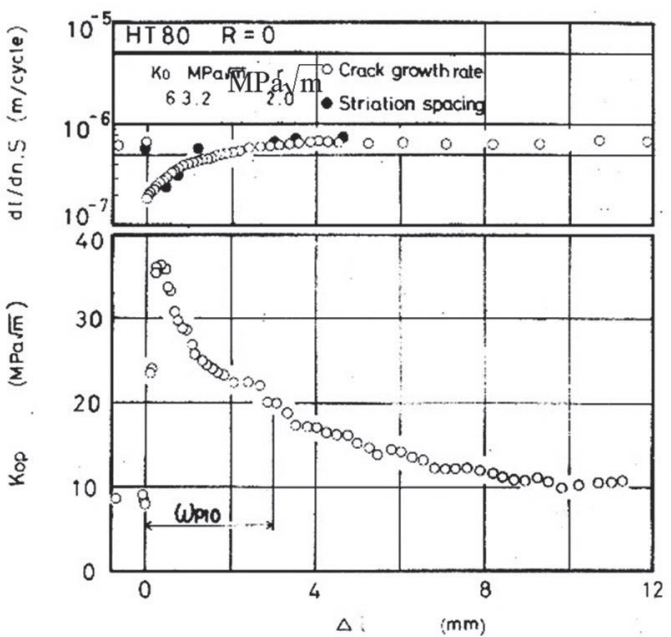

Fig. 7 Crack propagation rate and crack closure behavior following a single overload $\left(K_{0}=63.2 \mathrm{MPa} \sqrt{\mathrm{m}}, r=2\right)$

a maximum value. The crack propagation length showing this maximum value varies depending on the test conditions, and is approximately equal to the plane strain plastic zone size $\omega_{\mathrm{p}}$ 
owing to the single overload when the overload ratio $r$ is small or the reference stress intensity factor $K_{0}$ is low. However, it is approximately a fraction of the plastic region dimension when $r$ is large or $K_{0}$ is high. Although the raised opening point descends along with the subsequent crack propagation, it returns to the steady value under a constant amplitude load after the crack has propagated by approximately 2 to 4 times the plastic zone size $\omega_{\mathrm{p}}$ under all test conditions. However, the crack propagation rate in all cases is the lowest immediately after overloading and then recovers with the crack propagation, and returns to the steady propagation rate under a constant amplitude load in the plastic zone size $\omega_{\mathrm{p}}$.

The points indicated by the solid symbol in Fig. 7 are the mean values of the striation spacing at the center of the test specimen measured by fractography using a scanning electron microscope. No striations were observed immediately after overloading, and the striation spacing observed after the crack had propagated by approximately $0.5 \mathrm{~mm}$ is almost consistent with the macroscopically measured crack propagation rate. Hirano et al. reported ${ }^{18)}$ from the measurement of striation spacing following a single overload of aluminum alloy 2017, that delayed retardation was observed inside the specimen, and the crack propagation length indicating the maximum delay was approximately half of the maximum delay point (approximately $1 / 3$ of the plastic zone size) of the crack propagation at the surface. Applying these factors to the test condition, $\omega_{\mathrm{p}} \approx 3.0 \mathrm{~mm}$; thus, the point of $\Delta l \approx 0.5 \mathrm{~mm}$ inside the specimen corresponds to the maximum delay point. Therefore, it is not possible to determine whether a delayed retardation occurs because the crack propagation rate before overloading is unknown. It can only be determined by measuring the striation spacing shown in Fig. 7, but if a delayed retardation occurs, then striations with wider spacings than the striations observed at $\Delta l=0.5 \mathrm{~mm}$ in the range of $\Delta l$ $=0.5 \mathrm{~mm}$ or less are observed. However, considering that no striations are observed in that region and that the resolution of the unloading elastic compliance method is approximately 50 $\mu \mathrm{m}$, it is considered that delayed retardation does not occur at a distance beyond this resolution at least in the materials used in this study.

Next, the following dimensionless quantity $\lambda$ was used to quantitatively evaluate the retardation phenomenon of the crack propagation rate $\Delta K_{\text {eff }}\left(=K_{\max }-K_{\mathrm{op}}\right)$ by considering the crack closure behavior

$$
\lambda=(d l / d n) /(d l / d n) *
$$

In the above equation, $(\mathrm{d} l / \mathrm{d} n)$ is the measured crack propagation rate, and $(\mathrm{d} l / \mathrm{d} n)^{*}$ is the crack propagation rate in the case of the constant amplitude test with $\Delta K_{\text {eff }}$ equal to the measured $\Delta K_{\text {eff. }}$

Figure 8 shows the relationship between the crack propagation ratios, $\lambda$ and the dimensionless crack propagation length divided by the plastic zone size. Fig. 8 (a) shows the test results when the reference stress intensity factor $K_{0}$ is fixed at 21.1 $\mathrm{MPa} \cdot \mathrm{m}^{1 / 2}$ and the overload ratio $r$ is changed. Fig. 8 (b) shows the test results when $r$ is fixed at 2 and $K_{0}$ is changed. Under all test conditions, the crack propagation rate conversely shows a retardation phenomenon despite the decrease of the crack opening point and increase of $\Delta K_{\text {eff }}$ because of overloading. Therefore, $\lambda$ exhibits a value smaller than 1 immediately after overloading. Subsequently, the retardation recovers as the crack propagates and the value of $\lambda$ increases. When $K_{0}$ is low or $r$ is small, $\lambda$ rises monotonously, and returns to the value of 1 at approximately $\Delta l / \omega_{\mathrm{p}}=1$; however, when $K_{0}$ or $r$ are large, the value of $\lambda$ increases to more than 1 because the degree of increase in the crack opening point is larger than the degree of recovery of the delay in the crack propagation rate, showing an acceleration phenomenon with respect to $\Delta K_{\text {eff. }}$ Subsequently, $\lambda$ decreases along with the decrease in the crack opening point and returns to 1 at approximately $\Delta l / \omega_{p}=2$ to 3 . From the above, it can be inferred that the retardation of fatigue crack propagation following a single overload under plane strain conditions cannot always be explained only by macroscopically measured crack closure behavior. Figure 9 is a scanning electron micrograph of the fracture surface in the vicinity of the overload point when the
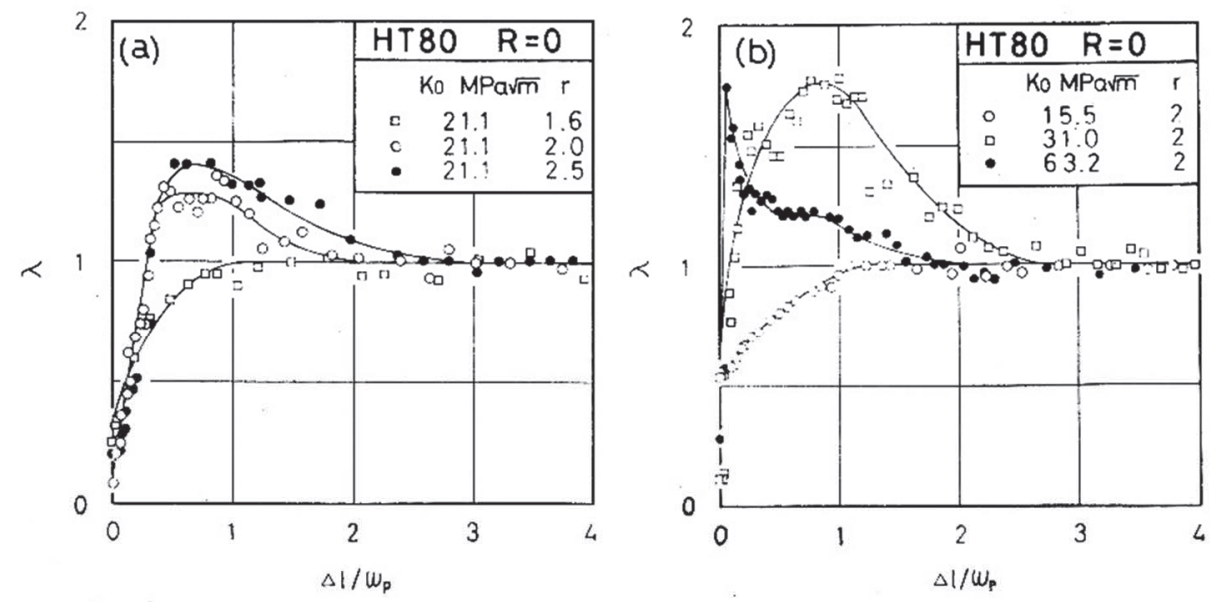

Fig. 8 Variations of crack propagation rate ratios, $\lambda$. 


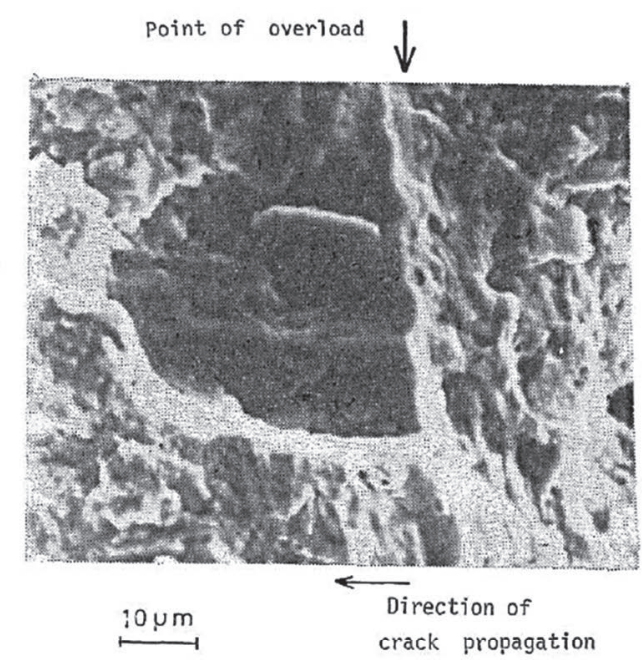

Fig. 9 Fractograph in thevicinity of point of overload.

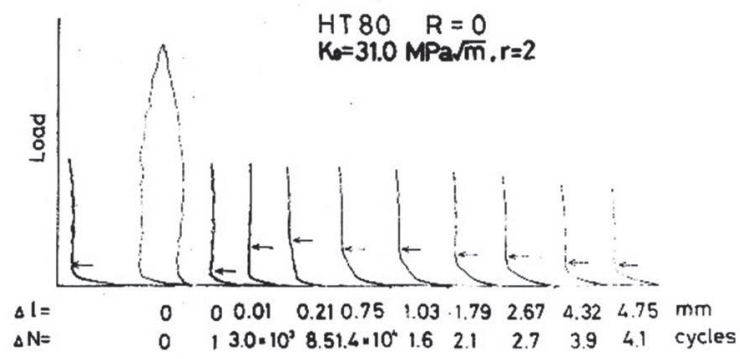

Fig. 10 Variation of load-differential displacement curves after a single tensile overload.

reference stress intensity factor $K_{0}$ is $63.2 \mathrm{MPa} \cdot \mathrm{m}^{1 / 2}$, and the overload ratio $r$ is 2 . It is confirmed that a large stretch zone is formed at the overload point and the crack reinitiated from the blunted crack tip.

Additionally, Fig. 10 is an example of load-differential displacement hysteresis before and after overloading in the case of the single overload test with $K_{0}=31 \mathrm{MPa} \cdot \mathrm{m}^{1 / 2}$ and $r=2$. The load-differential displacement curves show a large hysteresis width at the overload point, and the crack opening point indicated by the lateral arrows decreases immediately after overloading. Additionally, the opening point increases with repeated post-loading, but a clear two-step bend is observed in the hysteresis after the crack has propagated by approximately $0.21 \mathrm{~mm}$. In this case, the upper bending point corresponds to the compliance change owing to the closure behavior of the crack tip, and the lower bending point corresponds to the crack length from the overload. From this, it can be confirmed from the compliance change that the fatigue crack tip is blunted because of a single overload and that a new crack reinitiated from the bottom of the blunted crack by the subsequent cyclic loading. When the crack tip is blunted, the stress singularity at the crack tip decreases compared to the sharp fatigue crack although the stress range $\Delta \sigma$ at which the crack opens is the same; it is also possible that the crack propagation stops. The crack arrest and reinitiation because of the blunted crack are considered to be the reason why $\lambda$, which is organized in the apparent $\Delta K_{\text {eff }}$ in Fig. 8 , becomes 1 or less immediately after overloading. When a crack initiated from the blunted crack tip, the opening of the crack first opens the blunted crack tip, and opens the tip of the small crack generated from the blunted crack tip when the load increases. However, in the range where the length of the generated crack $\Delta l$ is smaller than the blunting amount of the crack or the plastic zone size, it is impossible to represent the elastoplastic behavior in the crack tip vicinity only with $\Delta K_{\text {eff }}$ considering the opening point of the crack tip. It may be necessary to consider a slightly wider range of deformation behavior including the blunted crack. This may be the reason why $\lambda$ becomes 1 or more in Fig. 8 considering the upper Kop. If $\Delta l$ increases and the elastoplastic behavior in the crack tip vicinity is represented only by the closure behavior of the newly generated and propagated crack, $\Delta K_{\text {eff }}$ makes it possible to evaluate the propagation rate and $\lambda$ returns to 1 , and the two-step bending of the load-differential displacement hysteresis is eliminated.

Recently, Hirano et al. reported that a delayed retardation in the crack appears because of a single overload on the test specimen interior measured by the ultrasonic method, and that the behavior is well represented ${ }^{19)}$ by the crack closure behavior. Other than the difference in material, the ultrasonic and compliance methods have different measurement regions, and exhibit variations in the measurement accuracy of the opening point and crack propagation length. The differences from this report are considered to be potential topics for evaluation in the future.

In nonstationary loads, there are also high-low two-step variable loads that cause the crack propagation retardation phenomenon similar to a single overload. It has been reported that the retardation in the case of the high-low two-step variable load can be effectively explained ${ }^{13)}$ by the crack closure behavior for a relatively high $K$ value. Although The crack tip blunts owing to the overload in the case of a single overload, the crack tip does not blunt even under a high load because the crack, which is a fatigue crack with a sharp tip, propagates in the plastic region formed by the successive cyclic loading. Therefore, because there is no noticeable change in the shape of the crack tip even when the load is reduced, it is considered that the crack propagation rate can be accurately evaluated by measuring the crack opening point when the load is reduced.

From the above, it can be deduced that the retardation phenomenon of the crack propagation because of the overload can be explained effectively by the crack closure behavior when the crack propagation mechanism does not change. However, if the crack tip is blunted owing to the overload and a crack is newly regenerated from the blunted crack tip with discontinuous crack propagation, the retardation phenomenon cannot be explained only by the closure behavior of the crack tip measured 
macroscopically from the change in compliance. It is therefore considered necessary to evaluate the crack propagation rate considering the variation in the crack propagation behavior.

Figures 11 and 12 are the results of the single overload test for the aluminum alloy A5083-O material under the test conditions where $K_{0}=9.3 \mathrm{MPa} \cdot \mathrm{m}^{1 / 2}$ and $r=2$. The crack propagation rate shows maximum retardation immediately after overloading, then gradually increases with the propagation of the crack and returns to a steady growth rate at approximately 1.2 times the plane strain plastic zone size owing to the overload. However, the crack opening point decreases once, owing to the overload, and then increases with the propagation of the crack and reaches the maximum value at approximately $1 / 8$ of the plastic zone size. Subsequently, the opening point gradually decreases and returns to the steady value with respect to the reference load at a crack propagation length of approximately 3 times the plastic zone size. From the above, it is deduced that the retardation of crack propagation following a single overload for the A5083-O

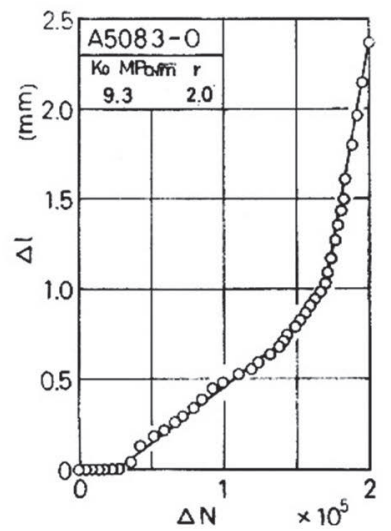

Fig. 11 Fatigue crack propagation behavior following a single tensile overload (A5083-O).

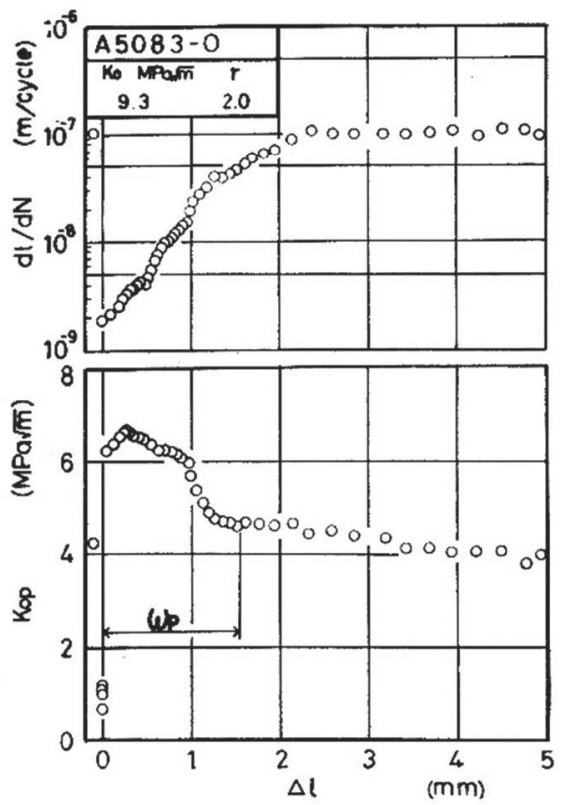

Fig. 12 Fatigue crack propagation rate and crack closure behavior following a single tensile overload (A5083-O). material is almost similar to that of the HT80 material. Additionally, the retardation cannot be explained only by the closure behavior of the crack tip measured macroscopically.

\section{Conclusion}

The following results were obtained by evaluating the delay phenomenon of fatigue crack propagation by a single overload test using high tensile strength steel HT80 and corrosionresistant aluminum alloy A5083-O materials.

(1) According to continuous dynamic measurement using the unloading elastic compliance method, a delayed retardation occurs at the specimen surface under plane stress conditions. Maximum delay occurs immediately after overloading at the specimen interior close to the plane strain condition, and delayed retardation is not observed.

(2) The retardation of the crack propagation under plane strain conditions does not correspond to the behavior of the opening point of the crack tip. Additionally, the retardation after overloading cannot be explained only by the closure behavior of the crack tip measured macroscopically from the compliance change.

(3) The load-displacement hysteresis after overloading shows two-step bending. It was also confirmed from the fractographic study that the fatigue crack is blunted because of the single overload and then regenerates. This discontinuity in the crack propagation is considered to be one of the reasons why the retardation cannot be explained only by the closure behavior of the crack tip. For retardation accompanied by the crack tip blunting, it may be difficult to evaluate the accurate propagation rate without considering the crack closure as well as the variation in the crack propagation behavior.

This research was supported by the Grant-in-Aid for Scientific Research by the Ministry of Education and Science. We would also like to express our graduate to Osaka University students, Takuji Tsugawa and Keiichi Tanaka in carrying out the experiments.

(Lectured at the 59th National Convention of The Japan Society of Mechanical Engineers on 20th October, 1981 )

\section{References}

1) E. F. J. von Euw, R. W. Hertzberg and R.Roberts, "Delay effects in fatigue crack propagation", ASTM STP 513, Vol.230 (1972).

2) R. P. Wei and T. T. Shih, "Delay in fatigue crack growth", International Journal of Fracture, Vol.10, No.77 (1974).

3) J. Schijve, "Observations on the Prediction of Fatigue Crack Growth Propagation Under Variable-Amplitude Loading", ASTM STP 595, Vol.78 (1976), S.Matsuoka, K.Tanaka, F.Kohzu, "The effect of specimen thickness on the 
retardation phenomena of fatigue crack growth following a single overload", Transactions of the JSME, Vol.45, No.1135 (1979).

4) G. J. Petrak, "Strength level effects on fatigue crack growth and retardation", Engineering Fracture Mechanics, Vol.6, No.725 (1974).

5) O. E. Wheeler, "Spectrum loading and crack growth", Transaction of the ASME D, Vol.94, No.81 (1972).

6) J. D. Willenborg, R. M. Engle and H. A. Wood, “A Crack Growth Retardation Model Using an Effective Stress Concept", AFFDL-TM-FBR-71-1 (1971).

7) S. Matsuoka and T. Tanaka, Engineering Fracture Mechanics, "The retardation phenomenon of fatigue crack growth in HT80 steel", Vol.8, No.507 (1976).

8) A.Ohta, C.Masuda, "A few problems related to fatigue crack propagation behavior observation", JSME Proceedings, (1977).

9) S.Matsuoka, K.Tanaka and F.Kohzu, "Effect of stress ratio of reference load on fatigue crack propagation retardation phenomenon", Transactions of the JSME, Vol.46, No.397 (1980).

10) K.Tokaji, Z.Ando and K.Morikawa, "Effect of sheet thickness on retardation behaviour of a high tensile steel", Journal of the Society of Materials Science, Japan, Vol.29, No.808 (1980).

11) P. J. Bernard, T. C. Lindley and C. E. Richards, "Fatigue Crack Growth Under Spectrum Loads", ASTM STP 595, Vol.78 (1976).

12) W. Elber, "The Significance of Fatigue Crack Closure", ASTM STP 486, Vol.230 (1971).
13) M.Kikukawa, M.Jono, K.Tanaka and M.Takatani, "Measurement of fatigue crack propagation and crack closure at low stress intensity level by unloading elastic compliance method", Journal of the Society of Materials Science, Japan, Vol.25, No.899 (1976).

14) M.Kikukawa, M.Jono and Y.Kondo, "Evaluation method of fatigue crack growth behavior and propagation rate under variable load in low $\mathrm{K}$ region", Transactions of the JSME, Vol.47, No.468 (1981).

15) J. M. Baik, L. Hermann and R. J. Asaro, ASME AMD, Vol.47, No.33 (1981).

16) M.Kikukawa, M.Jono, Y.Kondo, T.Yamagi and K.Yamada, "Fatigue crack propagation and crack closure behavior under plane strain condition", Journal of the Society of Materials Science, Japan, Vol.29, No.155 (1980).

17) M.Kikukawa, M.Jono, K.Tanaka, Y.Kondo, F.Tabata and Y.Murata, "Use of mini-computer for accurate automatic-measurement in fatigue test", Journal of the Society of Materials Science, Japan, Vol.29, No.1240 (1980).

18) A.Hirano, H.Kobayashi, H.Nakamura and H.Nakazawa, "Fractographic study of the effect of a single overload on fatigue crack growth", Transactions of the JSME, Vol.46, No.1040 (1980).

19) K.Hirano, Y.Takagi, H.Kobayashi and H.Nakazawa, 31st Proceedings of Journal of the Society of Materials Science, Japan, 